\title{
The Results Framework of the Agenda 2030 for Sustainable Development and the Ebbs and Flows of International Development
}

\author{
Aderemi Oladele \\ Permanent Delegation of Nigeria to UNESCO
}

\begin{abstract}
By vision and design, the Agenda 2030 for Sustainable Development carries two integrated and distinct features, identified as both challenge and opportunity in international development. These are notably its game-changing "results framework" and an objective to "leave no one behind" - a political imperative linked to the concept of universality, which tends to close the margin between developing and developed countries in the agenda's applicability. These features do not only respond to change in approach to international development action for greater effectiveness, they also offer avenues for studies into susceptible changes in the perception of certain established concepts and rudiments, including those linked to reforms in global governance, management and Africa's specificity. Through a qualitative analysis of selected contemporary debates around the Agenda 2030, this essay aims to underscore some possible alterations to perceptions of international development within the framework of the Agenda 2030 for sustainable development. To further illustrate the results framework and universality of the SDG's examples were explored to highlight particularly implications for Africa as a development priority region.
\end{abstract}

Keywords: International Development; Sustainable Development; SDGs; Agenda 2030 for Sustainable Development; Results-Based Management; Results Framework; Development Effectiveness; Development Management; UN System, Global Governance; Public Policy.

\section{Introduction}

In contribution to the body of knowledge on the implications of the SDGs on the changing perspective of international development as a discipline and field of practice, this essay raises questions on selected emerging issues and trends which the advent of the Agenda 2030 for Sustainable Development generates. First is the increasingly blurred line between development actions at the international and local level, owing to the exigences of new methods of measuring and interpreting results. In this case, global priority actions, particularly in the case of Africa as this relates to the universality of the SDGs means that one can measure success of international development by the level of achievements recorded in the course of development action in a regional or local community. While also arguing that a major determinant of the causes of actions that led to the alterations in the "ebbs and flows" of international development from the SDGs 
declaration, the paper examined important changes in approach to management in the United Nations System, as the institution under whose purview the Agenda 2030 has been promulgated and being implemented. An introductory debate on what lies ahead and could further assist our understanding of the subject of international development, the interdependence of challenges and alternative futures, henceforth and beyond 2030, were also tabled.

\section{International Development and its "Ebbs and Flows"}

International development is described as development in an international scale. Difficult to ascribe a straight forward definition, its focus has shifted from sole economic development and improving the wellbeing of developing countries to include the interaction between international, states and local actors in resolving development challenges that grows from local to international policy spectrum. From the social science perspective, international development has been described as everything happening around us, while in a broader term associated with economic development, which also has various competing perspectives. Meidan (2018) opined that since "development work promotes international and inter-organizational connections and collaborations, with the understanding that regions and countries under conditions of poverty, or a relatively low level of development, can benefit from international assistance or collaboration", international development is a "work of assistance and cooperation". The international assistance work, "was established with the founding of the Bretton Woods organizations after World War II, among them the World Bank and the International Monetary Fund, established to aid various countries to regain their strength after the war and the secret of international development is "cooperation".

With models such as "Development as Growth and the Linear-Stage Theories"; "Structural Change"; "Interdependence Revolution" and "Neoclassical Dependence"; as well as "Contemporary Models", articulated by Todaro and Smith (2006), international development evolves both in physical, contextual and thematic perceptions and involves changes in focus and understanding of the world configuration, challenges, approaches and understanding of the ways they are solved. International development also involves institutions and the purpose and manner in which they are established, including the induced changes and reforms necessitated by ever evolving understanding of best practices. International development has an international comparative context and country-wise development oversight (Todaro and Smith, 2006).

Based on these assertions, my subscription on the "ebbs and flows" of international development is a reflection of how given phenomenon influences movement and direction of thigs and the change, either progressive or otherwise, in the events, issues, institutional transformation, classification and progress that shape the landscape of international development overtime. The characteristic of global governance and institutional settings after the First World War with the birth of the United Nations Organization and the resultant effects on international and intergovernmental relations to date is a vivid example of this so called "ebbs and flows", while the consciousness of changes in the world order, such as the evolving nature of war and the notion of peace as well as other landmark issues like globalization, the information and communication technology revolution, new approaches to environmental and climate change issues, poverty eradication and the ever-growing consciousness of the intertwining nature of elements in development, constitute these ebbs and flows.

The movement and changes in perception of certain terms and action orientation in international development are therefore dubbed the "ebbs and flows", while elements of adaptations in the "quests to achieve effectiveness of development actions" and the abounding of a "results culture to achieve impacts at the local level" are at the center of these "ebbs and flows". It 
is proven that these are also responsible for changing vocabularies, international classifications, institutional reforms in countries and the United Nations system as well as a fusion of the local and international dimensions of action orientation, new focus on cooperation and institutional capacity building for successful implementation of the SDGs, which constitutes standalone goals 16 and 17.

\section{The Sustainable Development phenomenon and the Ebbs and Flows of International Development: 1972-2030}

It cannot be overemphasized that sustainable development as a concept constitutes a paradigm shift in development policy making. In defining the characteristics of sustainable development, I argued in a 2009 article that:

"There are two fundamental global angles by which one can view sustainable development in the present dispensation: sustainable development as a management tool and; sustainable development as a multidisciplinary science. Between 1992 and now, our perspectives of the term have been concretized by these two factors. Universities now offer sustainable development as a course of study while governments, business and development organizations continue striving to integrate the concept into working procedures. The former connotes that the subject is developed to the level of academic and professional discipline, taught in classes and the latter represent the fact that it is seen as a tool in public and private institutional management" [Oladele, 2009).

While, as at then, the notion of sustainable development as a multidisciplinary science was already influencing action within the framework of the Millennium Development Goals (MDGs), as well as in the apparition of academic programmes and disciplines related to sustainable development, the notion of "sustainable development as a "management toolkit" was just beginning to take its root. Without doubt, the configuration of the Sustainable Development Goals (SDGs), as contained in the Agenda 2020 for Sustainable Development, and the amount of efforts towards management reforms in the UN and government's administrative apparatus, to meet the institutional requirements for SDGs implementation have now reaffirmed this "prediction".

It should be recalled that the journey to the ground breaking integrated policy began with the 1972 World Conference on the Human Environment, held in Stockholm, where environmental issues were brought to an international round table for the first time under the auspices of the United Nations. The 1992 UN Conference on the Environment and Development, held in Rio de Janeiro, would later emphasize a vision of threefold development pillars of "economic development", "social cohesion "and "environmental sanity". Prior to the Rio Conference, a report of the World Commission on the Environment and Development, Our Common Future, published 1987 had defined the term sustainable development as "the ability to meet human needs today without jeopardizing the ability of the future generations to meet their needs".

This culminated in the Rio Conference in 1992, where the "Agenda 21", the "UN Framework Convention on Climate Change (UNFCCC)" and the "Convention on Biodiversity" were adopted. Afterwards, many more consensus, declarations and agreements have come to expand the scope of sustainable development, resulting in a series of fragmented policies, addressing the economic, social and environmental pillars of human development. It is within this 


\section{Technium Sustainability}

context, that in the year 2000, the MDGs were adopted with development objectives which articulate elements of all the three pillars of sustainable development and introduced a timeline approach with a major theme of poverty eradication through concerted efforts. A 15-year timeline approach and the firm political coordinating effect of the MDGs also particularly revolutionized progress in fostering development, especially in developing countries (Katagum, 2016).

With different evaluations that show a mixture of success and timid progress, especially in developing countries at the approach of the MDGs timeline in 2015, they were succeeded by the SDGs in September of that year. The SDGs is said to be a collection of fresh articulated universal development objectives, with integrated implementation strategies and political commitments by Governments for sustainable development from 2015 to 2030. They benefit from the international progress in "delivery-as-one", where a coordinated and integrated approach will ensure the achievement of targets. Whereas the MDGs are identified as more of a collection of "global goals", that is - a global agenda that addresses developing countries, within which all other countries were to participate, the "universal" nature of the SDGs, grouping seventeen goals that address the needs of both developing and developed countries in one articulated policy blueprint, were designed to be all inclusive and an agenda that "leaves no one behind".

Figure 1: The 5 Ps of Sustainable Development

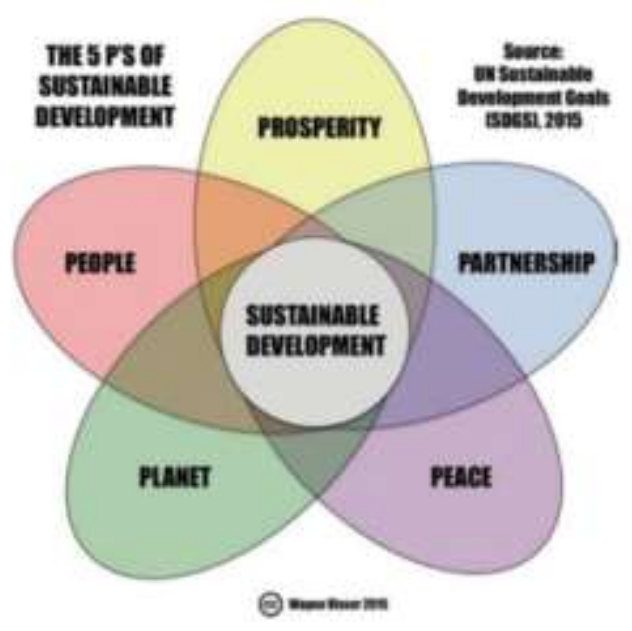

According to the 2018 World Public Sector Report, the Agenda and the SDGs have elevated the status of sustainable development on the international policy agenda, increasing the legitimacy and relevance of integrated perspectives and approaches. In addition, the explicit focus of the Agenda on institutions provides an impetus for governments to devote more attention to finding institutional models and public administration approaches that effectively support integrated action by different development sectors, ministries and agencies. These positive changes in legitimacy and relevance are further supported by progress in the scientific understanding of interlinkages among sustainable development issues on the one hand, as well as by the development of analytical methods, tools and information systems that support integration in public institutions in practice (United Nations, 2018). Figure 1 depicts the "five Ps" of Sustainable Development and their integrated/intertwining nature for development management purpose. 
The Agenda 2030 is therefore an ambitious agenda with a significant shift in approach to international development. Its 5Ps which broadens its coverage to include all known intertwining focus on people, planet, prosperity, peace and partnership address development aspirations in such an unprecedented manner, spurring action toward addressing common problems, while all countries are expected to evaluate how the SDGs could be implemented in their national contexts. An important result of this new approach is that the SDGs have framed development "beyond aid" and beyond an aid industry based on North-South transfers, implying new partnership approaches and the erosion of traditional donor-recipient relationships (Paul, 2016). Its integrated perspective has become the mainstream approach to development, increasing the political salience of integrated policy (UNDG, 2016). As such, the gradual policy process which started with the 1972 Summit therefore paved the way to a policy framework that has and will continue to determine the direction of international development, global governance and management, as a tool kit with great influence on the characteristics, terminologies and future orientation and understanding of international development, a selection of which are expatiated in the succeeding section.

\section{The "Results Culture" and Influence on the ebbs and flows}

The Agenda 2030 comprises targets, deadlines, indicators and data that are the prerequisites of a coherent results framework. It maps out goals to be achieved, changes to be pursued, and impact to be sustained. As development results are about demonstrable change across economic, social, environmental and political spectrums, the SDGs targets aim at real life outcomes and change, and the 2030 Agenda expresses the common aspirations of the world community with respect to development change. Progress on the SDGs, especially their targets, reflects achievement of development results, to which international development co-operation is contributing (OECD, 2017). The Agenda's overarching objective of Leaving no one behind also involves targets that set a high bar in terms of disaggregated development results, since it endeavours "to reach the furthest behind first" (OECD, 2017), while its four components of clear visions and principles; results framework; means of implementation; and follow-up and review mechanism represent a landmark for an impact-based international development policy which covers the economic, environmental and social dimensions of development.

Inherently a mixture of intended outcomes, desirable policies and necessary processes of collaboration and partnerships, the Agenda offers the best approach to strengthen results-based decision making in development co-operation - as the SDGs address real life change for people, more inclusive societies, and sustainability in all its dimensions (OECD, 2016). This mark and focus on input, outcomes and real impacts subscribe to the principles of results-based management and development effectiveness in international development which are also part of the pillars of reforms in international institutions, particularly the United Nations (see figure 2 for the Impact Component of the Agenda 2030). Also, the Agenda's provision, whereby a set of indicators and a monitoring framework accompany the goals and countries commit to engage in systematic followup and review of the implementation to maximize and track implementation progress also enhance accountability to citizens and support and foster international cooperation and mutual learning (UNDESA and INTOSAI, 2017).

One then cannot but agree to the fact that the Agenda 2030 is a landmark success and a culmination of proposals to improve on development actions, institutional reforms and results in international development. It is indeed a departure from the status quo of policy discourse and politically-influenced business-as-usual approach to international relations and development cooperation. The mix of technocratic and political engagement which relies on results/impact- 


\section{Technium Sustainability}

oriented rather than process-based action is a reflection of a new international development system and ebbs and flows in continuous evolution.

Figure 2: The Impacts Component of the Agenda 2030 for Sustainable Development

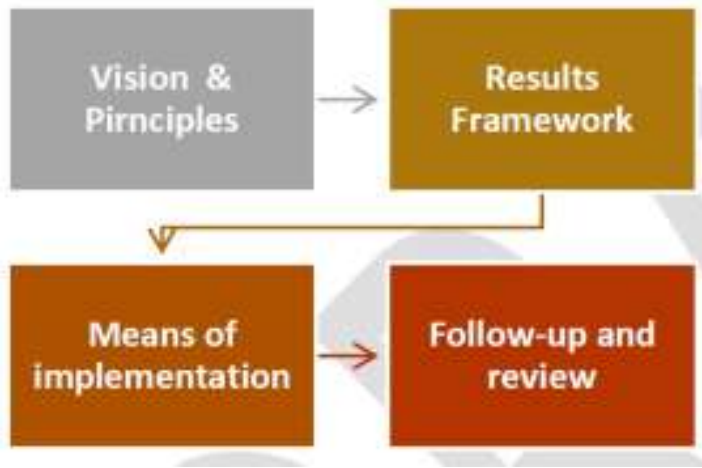

Source: UNDESA \& IDI, 2017

\section{The "Agenda" as a Universalist Integrated Development Framework: Are International Classifications Fizzling Development Geopolitics?}

International development dwells on the level of development on an international scale and is the basis for international classifications such as developed countries, developing countries and least developed countries. Yet, the universalist nature of the Agenda 2030 and its objectives of leaving no one behind, equity, rights-based approach development, and aiming at non-quantifiable results in the form of empowerment, has been designed to under-stress this international division along development levels. The notion of universality of the SDGs, rather than being globalist in nature , was indeed set to erase the dichotomy of developing, developed and least developed, largely present in the precursor MDGs. So is the fact about making recommendations on actions that apply to every country and leaving each one to adopt the relevant aspects in accordance with national development objectives and priorities. These in a way defile the traditional international development framework where policies are made with special consideration for countries of the South while the West as superior partners are looked upon for assistance in all ramifications.

Although this consciousness was based on the understanding that development challenges must be seen as are universal, where, for example, it is a known fact that poverty exists everywhere, but only in different dimensions and gravity. It should be recalled that international and geopolitical divisions is a strategy to help in cooperation and sharing of best practices, as well as strengthening negotiation capacity for countries with identical population, geographical location, colonial and common economic histories etc. The proliferation of regional, geographical, geopolitical regrouping, in that regard, gave birth to the likes of G8 (8 World Largest Economies); E9 (Nine most populous countries cooperating for education development); Non-Aligned Movement (NAM); and many others, especially within multilateral institutions.

At the centre of how relevant these divisions are to implementing the SDGs and how this could change our preconceived notion of international development from a broader perspective one can question the effects the SDGs Universalist approach on the continuity of the aforementioned divisions and the benefits thereof. Hans Rosling, the late Swedish statistician and 
global health expert addressed this issue in the book titled "Factfulness". In what is referred to as Rosling's final attempt to change the fatalistic ways that he says most people view the world, and stressing that statistically speaking, things aren't as bad as we might think, he affirmed that the world rely too much on a set of "emotion-fueled "instincts" to frame the state of the world, painting a much gloomier-than-reality picture of everything from global education to healthcare and natural disasters. He then suggested that the binary framework of one "developing" world pitted against another "developed" world be replaced with a four-tiered system to talk about income levels (Brueck, 2018).

These four-tiered income level classifications, namely, Low-income economies, Lowermiddle-income economies, Upper-middle-income economies and High-income economies (Rosling et al., 2018), proposed as replacement by Rosling, and having already been adopted by the World Bank (World Bank, 2018), is a pointer to the fact that such a classification may gradually replace the "developing" and developed" classification to corroborate the necessity laid by the SDGs to alter some traditional "given attributes" in international development. In the face of the growing popularity and expected impacts of the less-traditional prescriptions of the Agenda 2030, the question on whether this international classification and others of geo-political nature would fizzle out in the future to be replaced by more conforming and results- oriented classifications and terminologies to describe differentials in development progress lingers on. While it has been ascertained that with Globalization, economic frontiers tend to disappear, should we conveniently say that it is now the turn of development frontiers to disappear in our vocabularies and outlook to international development based on SDGs dictates? This sort, we believe, would somewhat continue to shape our thinking of the future of international development as the process of implementing the SDGs unfolds.

\section{6. "Glocal" Development: Local as the new Global?}

I draw the idea of "Glocal Development" from Francesc Xavier Grau's concept of "Glocal" University (Grau, n.d.), which speaks of the role of universities as community developers with international influence and research relevance. It is about engaged university with local, regional and international relevance, who are able to influence their communities in development as a new and important mission. Transposing this idea into international development and in the light of the above analysis, one may say that "glocal" development is a new approach whereby thoughts of local impacts dominate worries about achieving development results while actors remain relevant in the tracking, measurement, programming and reprogramming for greater effectiveness, leadership and engagement at both the local and the international dimensions. This international outlook with dominance of focus on the "local" as the core of where achievements are measured tends to rephrase the narrative of "think globally and act locally" to that of "think locally and act locally" but remaining relevance globally.

The saying "think globally and act locally", first used in a development context by the environmental movement in the 1960s and 70s (TGCI, n.d.), grew in development practice since the late 1980s to become a watchword. Its invention indeed was part of attempts to sway from the known "one-size-fits-all" approach to planning development programmes at the international level, with the thoughts that strategies and procedures do not work the same way everywhere else. It was also a statement that reminds that, while local understanding and solutions are necessary for equitable development, a global awareness mindset of development and environmental challenges should encourage best practice while acting to advance development in local communities. From a rather narrow perspective, it could connote that an international mindset is required to act 
appropriately at the local level and that the "international" is more "professional" and its view of the world and challenges that surrounds it are superior and therefore a prerequisite to achieving results. This could however also be interpreted to mean that the most valuable lessons for effective local actions directly or indirectly should emanate from the international and global view or a world-wide issues evaluation and hypothesis on the state of the environment and development.

This notion may have currently changed to give way to more of "local thinking" on the specificities of needs that lead to appropriate and effective actions both at the international and local perspectives, as more essential ingredients for sustainable and equitable development. Although the fact still remains that cooperation is at the center stage of international development as "no one or country is an island on its own", the results and impact framework of the Agenda 2030 requires that attention must be on the real impact on recipients and situations at the tail end of development - which is the "local". The process of policy negotiation towards the Agenda 2030 is an example of the growing importance of local-context-based policy for effective development. This policy process was record breaking in the sense that there was an all-encompassing local, national, regional and international consultation which gave birth to the goals, targets, indicators, means of implementation and follow-up and review process. It took cognizance of taking the matter from the grassroots and through the whole hierarchy of policy consultation from the bottom to the top. For the first time, the African Union Commission, for example, had an input in the form of an African Common Position (CAP) on the Post-2015 Sustainable Development Goals, which was well elaboration and led to the inclusion of the "peace pillar" of sustainable development among others. This feature in itself also proves the level of focus on the local needs, aspirations and expectations, as well as consideration for culture, social compatibility and wellbeing before the Agenda became a universal integrated sustainable development policy.

The goals also reflect an understanding of the focus of action and the fact that it was fashioned after outcomes and impact on people as well as change in everyday lives around the world. Goal 1 which addresses "zero poverty", for instance, has its targets 1 and 2 specifying that by 2030 , extreme poverty for all people everywhere, measured as people living on less than $\$ 1.90$ a day, should be eradicated; and by 2030, aims to reduce, at least by half, the proportion of men, women and children of all ages living in poverty in all its dimensions according to national definitions, are specific objectives focusing on impact at the local level. The Agenda 2030, as with many other parallel or separate processes that brought international relations, institutions and capacity building efforts to the level they are, seem to look beyond "acting locally and thinking globally" while "local" tends to become the new "global" in the real sense of it. Furthermore, the United Nations reforms that started in the 1990s emphasized decentralization and results-based approach as two main pillars. Decentralization, in this regard prioritizes more presence of professionals at the local level (or in the fields) rather than retaining more qualified professionals at headquarters - and, as such, putting the local dimension at the center of gravity, where impacts of development efforts should be mostly felt.

In effect, the SDGs with its universal outlook and overarching objective of "leaving no one behind" reinforces decentralization, where success or failure of development policy is no more over concentrated on international politicking on the global scale but rather on concrete efforts with the local context in full view. It suffices then to say that once policies are processed and passed, any clues as to the impacts of these policies and corresponding actions and impacts is on function of what changes at the grassroots levels and the synergies within countries based on fields-level assessments and reviews and not what the great experts and gurus at organizations' headquarters have to say. This, in essence corroborates the notion of priority for local action and "success at the local level" as the essence of international development endeavours. 


\section{SDGs Implementation as a Call to More Reforms for effectiveness in the United Nations System and States' Institutions}

It is important to stress, as Chidozie and Aje (2017), that international organizations are predominantly innovative capacity-building measures for the conduct of bilateral and multilateral diplomacy in an increasingly complex and symbiotically interdependent global community. Indeed, international organizations are important actors in international relations for the conduct and operations of global governance. From our thesis on "glocal" development, the fusion of local, national, regional and international ecosystems in development practice to produce results, tends to narrow the link between international institutions and national administrative apparatus while the necessity of effectiveness and efficacy has become very strong for a successful implementation of development programmes. This thin distinction is one of the core competences of development management as a discipline, which not only views public administration as a reflection of international policies as they affect international and local action, but place greater emphasis on local evidence to measure progress and, ultimately, impact. As stated earlier, the United Nations' involvement in local process through a dedicated Department serves as evidence to the importance of this fusion tendency.

The Agenda 2030 in fact serves as a paragon for international organizations and global governance agenda and therefore an opportunity to redress the traditional methods of development administration. The opportunity presented must also see reforms towards SDGs implementation as a sign of continued innovation to meet the dire need of good and effective global governance for local development impacts (Chidozie and Aje, 2017). This thesis sees the results framework of the SDGs as an all-encompassing and overarching agenda that covers all aspects of managing for development in international organizations, with a view to producing effective results down the channel. The thesis advocates that the offering of the SDGs' as a holistic global development blueprint, presents a good reforms opportunity for the needed pragmatic approach in the treatment of overlapping responsibilities that the SDGs emphasize, thus a high point in the practice of international development "multisectoralism".

In the same vein, as reprogramming is recommended in Results-Based Management, whereby focus is on achieving end results without a limit to the number of times development programmes are rethought and reshaped, there is, in principle, no end to a project, including reform and transformation of carrying institutions, until the desired impact is attained - unless there is a realization that such projects are not viable. With the challenge of an integrated approach to implementing the SDGs, where the intertwining of sectoral goals calls for a new and revised level of inter-ministerial or inter-agency management, new patterns of operation are required. Appropriate, radical and intensive reforms or total transformation of management and programme implementation process that goes beyond our current endeavours.

This is why the UN has launched a huge reform agenda aimed at enhancing its actions to attain the Sustainable Development Goals ahead of 2030 by ensuring more effective capacities to tackle conflict, sustain peace, and improve the UN's internal management and ability to deliver, as expressed in a December 2016 UN report (UN-ECOSOC, 2017). Since assuming office in January 2017, the present Secretary General, António Guterres, has continued to emphasize on the need for reform to deliver on the SDGs and this has become a hallmark for UN's preparedness to assist Member States to achieve the corresponding objectives.

The three reform tracks address the fragmentation and bureaucratization of the UN system, which causes gaps, duplication of work, and resource drainage and aim to create a more 
accountable and effective UN system that delivers better on the ground, by adopting a needs-based approach centered on developing country-contextual responses. The focus is on prevention and on increasing collaboration within and among the three UN pillars (development, human rights, peace and security), including through stronger integrated planning and risk management capacities and simplified procedures (Lebada, 2018a).

Given that effective, accountable and inclusive public institutions are essential to achieving the Sustainable Development Goals, as laid down in SDG 16, governments have the primary responsibility for implementing the SDGs and ensuring follow-up and review over the coming 15 years, at the national, regional and global levels. One of the first steps governments should take to implement the Agenda is to shape the institutional arrangements for steering the implementation and reviewing progress. Public administration - the cornerstone of government's work- plays an essential and critical role in improving people's lives. Reinventing public administration is therefore primordial as a way forward. In effect, where capable administrations are lacking, governments are incapacitated; and where governments are incapacitated, sustainable development falls short. The reform is therefore also tailored to assist countries in readying their institutions and public administrations for realizing the SDGs and in making them effective, transparent, accountable and inclusive (UNDESA, n.d.).

Furthermore, the Agenda and the SDGs increased the legitimacy and relevance of integrated perspectives and approaches. The explicit focus of the Agenda on institutions therefore provides an impetus for governments to devote more attention to finding institutional models and public administration approaches that effectively support integrated approaches. These positive changes in legitimacy and relevance are further supported by progress in the scientific understanding of interlinkages among sustainable development issues on the one hand, and by the development of analytical methods, tools and information systems that support integration in public institutions in practice on the other (United Nations, 2018). This is perhaps why the UN Division for Public Administration and Development Management, which delivers on this mandate through conducting analytical work and research to support the Committee of Experts on Public Administration and building capacities of countries, devoted its recent World Public Sector Report to this salient and principal endeavour of "how governments, public institutions and public administration can foster integrated approaches to the implementation of the 2030 Agenda and the Sustainable Development Goals."(United Nations, 2018).

Although capacity building for public administration has always formed part of international development practice, linking international policy process to national institutional activities and other public apparatus that channel development to the grassroots, the consciousness that developing countries, which had stunted development due to institutional deficiencies, either political, leadership or mainstream civil service, require some forms of direct involvement and assistance to meet the challenges of the SDGs implementation. The fact that this objective forms a separate Goal should assure some harmony in the intervention of the United Nations, its Specialized Agencies and other international organizations to include development management and institutional capacity building in all mainstream activities. This is already becoming evident in reforms introduced by some UN Agencies, where operational effectiveness remains a major component of strategic transformation and concern for field reform that touch on rearranging institutional mechanisms and relations with Member States, pointing to a new level of decentralization.

Moving forward, the results framework of the Agenda would continue to require reforms for institutions that are fit for the purpose of implementation. While the SDGs encourage institutional reforms in countries, early analysis also shows that the UN as anchor organization will 
continue the process as a means of shaping itself to deliver. Lessons from Funds, Programmes and Specialized Agencies that have take-up reforms and transformation processes in response to the SDGs exigencies have aligned to the integrated institutional approach and strategic, operational and programme delivery framework that prioritize assistance to Member States' institutional capacity building in addressing internal organizational issues for operational efficiency. The same goes for regional spaces in which reforms, for example in UNESCO, focus on "improving and clarifying the articulation, alignment and coordination of the various roles, functions and responsibilities for the Regional Sustainable Development Goals (R-UNSDG), Regional Economic Commissions and other regional entities"(Gigzen, 2018). This, as well as the ambition to develop clear partnerships between the regional and national entities, should take its form from the main UN approach as part of the alignment process and, above all, take cognisance of the need for adhoc alliances and unconventional procedures in tackling challenges.

\section{Mindset Shift for Organization Transformation and the Future of Development Institutions in the SDGs Dispensation}

From the foregoing, the question of which management systems in international development should we expect becomes paramount? In other words, are there plausible models of management, which reforms and transformations could adopt to face the challenges and take the opportunities the Agenda 2030 offers in developing effective international institutions of the future and what are the possible models for a paradigm shift?

Aaron Sachs and Anupam Kundu (2015) offered some insights in a 2017 article concerning organizations that meets today's complex management needs. The analysis focused on business organization but gave clues into what is required for organizations across board (profit or nonprofit), and is believed to produce a paradigm shift for UN management and manager's mindset in the face of the demanding fragmented policies inherent in the SDGs.

In their words, the most profound challenge we face today is how to build organizations that can change as fast as change itself - as what matters is that the entire organization is culturally aligned to become a responsive organization and the only measure that really matters for such change initiatives is becoming a responsive enterprise over the course of a transformation. Figure 3 below, used by Zachs et al to buttress their point, describes a shift from profit to purpose; from hierarchies to networks; from controlling to empowering; from planning to experimentation; and from privacy to transparency, as requirements for a transforming organization.

The ensemble of shifts connotes a departure from the "traditional" management mindset and what the focus should be in reforming to conform to today's necessity for effectiveness in profit, focus or impact. Although the focus of the United Nations earlier reforms have spread to cover many aspects of such shifts, bringing new innovation on delivery-as-one, budget streamlining, Results-Based Management and decentralization, issues like attaining the required level of transparency in the rather "opaque" administration systems still leave much to be desired.

We therefore probe Zachs and Kundu's "mindset shift" thesis by placing the question of the end results of the "shifts" at the centre of the SDGs exigencies and the future of management for development impacts in the context of the management systems of states and international institutions, particularly the United Nations system. It is worthy of note that some expectations from the mindset shift align with the thrusts of the "JAZZ" scenario, as coined by the World Business Council for Sustainable Development (WBCSD) on what global development process and focus will be between the year 2000 and 2050. In the JAZZ scenario, the challenge of crosscutting and intertwining development challenges requires that diverse players join in ad hoc 


\section{Technium Sustainability}

alliances to solve poverty, social and environmental problems in the most pragmatic way possible and in a form of dynamic reciprocity. It is a world of social and technological innovations, experimentation, rapid adaptation, much voluntary interconnectedness and a powerful and ever changing global market. High transparency would be an enabling factor where there would be a widespread availability information about ingredients of products, sources of inputs, financial, environmental and social data, government decision making processes, and almost everything else the end users want to know. Many players would be involved, and the stage itself is characterized by a global free market and sound value systems(Oladele, 2018).

Figure 3: Mindset Shift for Organization Transformation
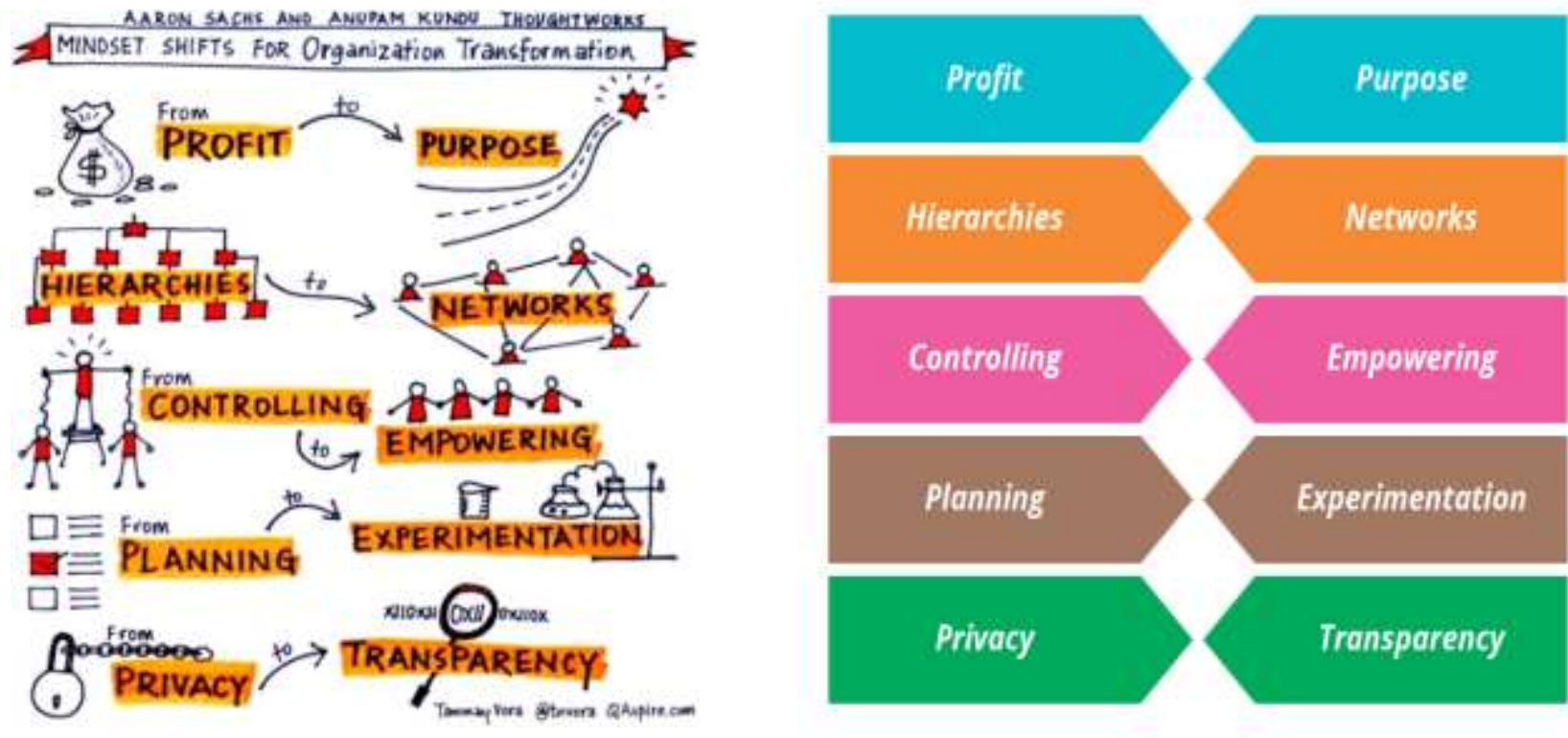

Source: Thoughthworks.com (https://www.thoughtworks.com/insights/blog/unfinished-business-organizational-transformation). Sketch on the left, courtesy of Tammy Vora (http://qaspire.com/2015/11/23/mindset-shifts-for-organizational-transformation/)

Governments would be involved mostly at the local levels, as ad hoc institutions would arise to solve particular problems. Agreements would be reached through mediations and ecologically compliant behaviours would be rewarded. Achievement of the new environmental and social standards would occur largely out of self-interest and the public would be made aware of transgressions and quickly act against entities that violate standards, while protecting the environment within a streamlined market mechanism and strong social and cultural diversity awareness framework. The winning government will be a government that recognizes the need to foster cooperation and partnership as well as encouraging leadership by responsibility with a solid believe in people oriented approach to state and development administration. Under this scenario, practical approach and a critical assessment of reality would matter. People, governments and organizations will no more do things as a matter of precedence but out of a genuine willingness to effect change and improve on human development with clear vision of end results in the living standard of the common man (Oladele, 2018).

It appears that the determining action in the SDGs implementation and the corresponding reforms strategies that seek to conform to the fragmented, yet holistic and cross-cutting nature of the Agenda 2030 are all pointing to a JAZZ scenario. As a blueprint for an all-encompassing 


\section{Technium Sustainability}

international development management policy, the strategy that will match the requirements for success in the SDGs must be out-of-the-box and incorporate pragmatism and ad-hoc alliances, multi-stakeholder approach, interconnectedness, personal and social accountability, alignment with multi-level development framework as well as the normative principles in development management as an alternative to pure public administration notion.

\section{The "Open-ended" Mindset Shift in organization Transformation}

In line with the assertions, we conclude that the latter elements would yield some open-ended end results, namely that moving from process to purpose will lead to greater focus on impact; the shift of mindset from hierarchies to network will give way to focus on Adhoc alliance and pragmatism; controlling to empowering will yield ownership and personal accountability; and experiment, which had taken the place of planning will further evolve to continued innovation; while the advocacy for transparency will evolve into social accountability by organizations willing to make impact. These elements are added to the "mindset shift" diagram by Sachs and Kundu to produce an Open-ended Mindset Shift in Organization Transformation as shown in Figure 4.

Figure 4: 'Open-ended’ Mindset Shift for Organization Transformation

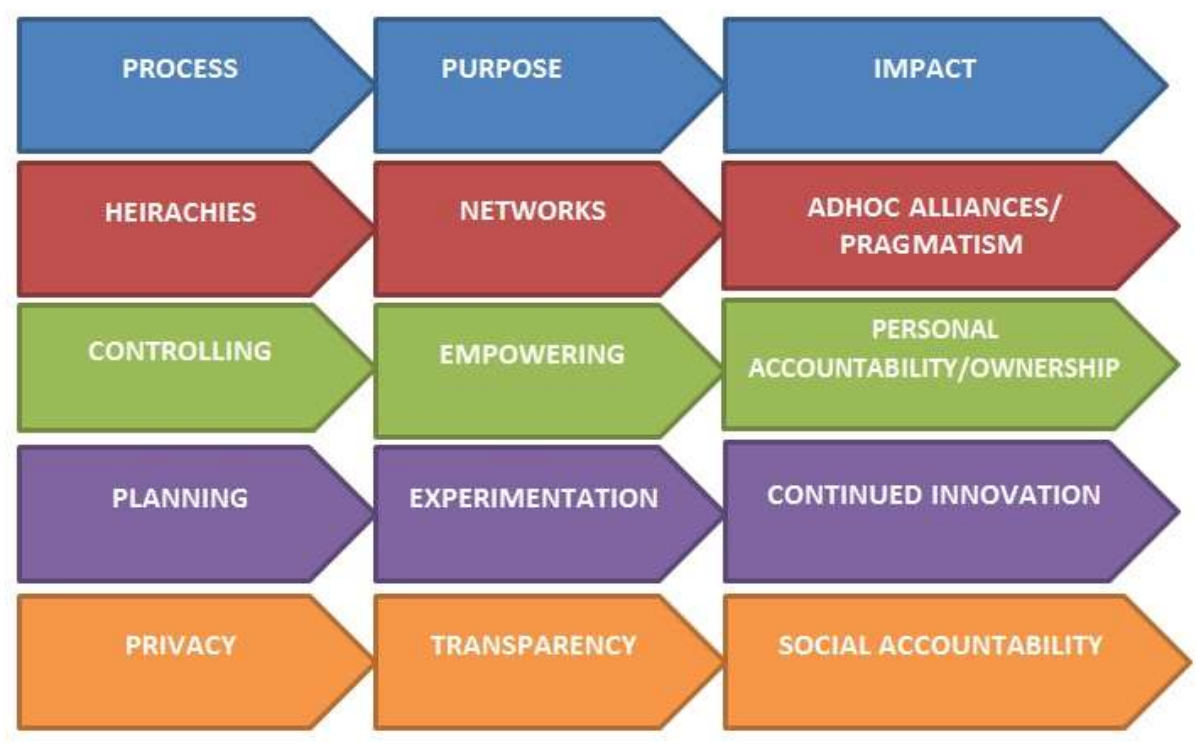

As development management evolved from the traditional process of development administration, modified to meet the accelerating need to be more responsive and applied customised approaches to different situations and conditions, the example of the UN General Assembly Resolution (72/279), already points towards a new mindset for the future of management. The Resolution aims at aligning UN development system with the 2030 Agenda through a "repositioning" process has called for: a "new generation" of UN country teams; "reinvigorating" the role of the Resident Coordinator (RC) system; revamping the regional approach; strategic direction, oversight and accountability for system-wide results; funding the UN development system; and following up on the repositioning efforts at the global, regional and 
country levels (Lebada, 2018b). It is evident that such a move summits to an Open-ended Mindset Shift. Intensified action towards the actualization of the objectives will require such shift for future effectiveness and feasible results in SDGs implementation.

Likewise, within the framework of UNESCO's Strategic Transformation, which aims at improving operational efficiency, improving communication, strengthening strategic partnership and deepening the Organization's presence in the world (UNESCO, 2018), apart from establishment a Sector of Administration and Management, will through the four thematic focus conduct further reorganization and place operation in the context of assisting Member States and regions to adapt to the demands of innovation to manage cross-cutting issues by shared responsibilities, while in the system itself the issue of delivery as one is further reinforced, is a vivid example of the coordinating effect the SDGs are bringing to the UN common system. It follows the thesis that the SDGs is both a challenge and opportunity for the UN system and this challenge may take reforms to yet unknown destinations where the fundamental features of development management such as norms, values, means to Institutional Agendas and Toolkit and Process feature largely as prerequisites assessable results.

Governance and public sector reforms in countries and reforms in the UN have and will continue to be hall-marks in demonstrable JAZZ-like scenario. Towards 2050, awareness will continue to grow on universal development action that warrants continued innovations, resultsorientation and ad-hoc alliances. Actions for the common good of all world citizens, either developed or developing and personal and social accountability for managers and institutions alike will be required where initiatives and willingness to deliver based on conviction, interest and the need to better people's lots. In this regard, Organizations on transformation journeys, according to Tammy Vora (2015), cannot afford to rely only on the technology innovations because innovation is a result of something deeper - innovation is a result of mindset, behavioral constructs, leadership and culture and these are the additional and essential ingredients, required for future development practice.

\section{Five New Levels of an "Open-ended" Mindset Shift in organization Transformation}

In the "Open-ended Mindset Shift", the results or expectations as shown in the flowchart might not necessary mean an overhaul of existing systems or organizational management structure, but a transformation of "mindsets", which will either or not lead to significant change structures but, inevitably, changes in approach, acceptance, cultural and behavioral constructs and mindsets that would guarantee results in the SDGs actualization. In representing the new levels of shift, the openended nature is depicted by right-pointed arrows, which show that the shifts are back-to-back, continuous and are susceptible to transform to new shifts as reality changes and the dynamics of development challenges continue to demand change. The components of the changes are expatiated as follows:

- Impact: The issue of impact as the mainstay of development results is not new. In the wake of concepts like development effectiveness, managing for development results and resultsbased management, the focus on impact rather than process, budget or outputs have become a best practice in measuring real change. For the SDGs and their results framework, the value of impact will become even greater as institutions and states grabble with objectives and indicators to measure real effect of development actions where they matter most - the locals. In this regard, the "Open-ended Mindset Shift" reasons that the movement from process to purpose and to the "impact" will culminate in a continuity of movement as the 
implementation of the SDGs deepens and may metamorphose into a yet unknown criteria to evaluate the value of every input and how they results into changes in the lives and situations of the end users of development in the nearest future.

- Ad-hoc Alliance/Pragmatism: The mindset shift from hierarchical movement and relationship to networking, which, in the "Open-Ended" model, gives way to ad-hoc alliances and pragmatism, is based on the fact that as many players and issues are emerging in the international development scene and their contributions cogent to results achievement under diverse circumstance, there will be need to coordinate the elements in a holistic way, while they continue to increase in number, different forms of manifestations, sometimes in manners that are hard to control. In this regard, the role of artificial intelligence, the civil society, business , NGOs and other entities of diverse, emerging and yet to be quantified nature, will also continue to increase. The mastery of their coordination with flexibility, open mind and pragmatic approach by diverse players will become a best practice. Ad-hoc alliance and pragmatism are required and are becoming evident as best approach to tackling the integrated and intertwining nature of the SDGs as alternatives to pre-determined process and systems, which, as a result of perceived failings, inspired the shift.

- Personal accountability and Ownership: In the Open-ended Mindset Shift, when controlling gives way to empowering, the resultant effect or target will be "personal accountability. Personal accountability is a norm and belief system that one is fully responsible for their own actions and consequences. It is a choice, a mindset and an expression of integrity and its components are Commitment, resilience, ownership and continuous learning. The premise is that organizations that will succeed in the face of lessdefined work scheduled due to the intertwining of issues, sectors and success factors, should be able to produce, shape or recruit employers that will take responsibility for their own actions through personal accountability and will display a high level of commitment, resilience, ownership and continuous learning. As Wakeman (2015) puts it, personal accountability is a mindset. And although this outlook could be viewed as old fashioned, organizational management in international development of the future would require a shift in employees and employers' mindset to work towards inspiring ownership through deliberate empowerment, to shape the development landscape for greater impact.

- Continued Innovation: Traditional planning system has today taken experimentation as a measure to inspire continuous innovation. The open-ended mindset shift highlights this as an end, which in itself carries a good potential for change in management perspectives in international development. With the notion that development challenges appear in an exponential rate and the alterations to the way we perceive problems and how to solve them are not also predetermined, every organization, regardless of their mandates and set-up in international development, would, by default, become laboratories of ideas and innovation for best practices. This manifestation and call for continued innovation is already there in the process that led to the Agenda 2030 for sustainable development, but its impact on the practice of international development will even be greater in the future.

- Social Accountability: Reforms around international organizations, especially the United Nations, have resulted in attempts to shift from opaque systems and notion of privacy to 
embrace transparency as prerequisite for effective results. In the Open-ended Mindset Shift chart, transparency will advance further to stress social accountability by institutions. It should be noted that social accountability for organization is more or less what personal accountability is for individuals. It is a step further from social responsibility, whereby there is a deliberate motive to share to stakeholders, actions and results. This is already visible in the reforms efforts in UNESCO where one of the thematic objectives of the strategic transformation framework is to improve communication. Improvement in communication is not only to showcase the works and progress in the organization, but a way by which the organization gives account to stakeholders, as well as a means to self-subject to scrutiny and external evaluation for continued improved efficiency. As social accountability measures an organization's state of being mindful of the emerging social concerns and priorities of internal and external stakeholders, the mindset towards it as a factor of success will continue to shape institutional management for successful implementation of Agenda 2030 and thus have an influence on the changing perception of international development.

It has continually been affirmed that "in a complex and intertwining development system such as we currently have, changing the mindset is what matters most". Although operating in an Openended Mindset shift may not physically change management structures (which it often does), the opening of management and development managers' minds to embrace complexity and to manage change in ways that soothes adaptation and actions is required to achieve impacts and results. This is what we believe will shape the attainment of the Sustainable Development Goals, as well as our perception of international development management.

\section{Africa and the Agenda 2030: Opportunity for Ownership, Results Culture for a New Renewal}

From the analysis of the preceding sections, the Agenda 2030 for Sustainable Development in itself also represents opportunity and challenge for Africa. It should be recalled that the process of preparing the Agenda, took into account the inputs of African governments $n$ the form of the Common African Position (CAP) on the Post 2015 Sustainable Development Agenda. The CAP was an opportunity to inter alia bring to the fore, such trends as population growth and the youth bulge, urbanization, climate change, inequalities and peace that became integral parts of the SDGs. It also reiterates the importance of prioritizing structural transformation for inclusive and peoplecantered development in Africa (UNECA, 2018). This shows that the SDGs were drawn in consideration for Africa development priorities. Secondly, the Agenda 2030 was drawn to reflect the African Union Agenda 2063, the Africa we want, published in April, 2015 and pave way for a side-by-side implementation, presently witnessed.

Given that Africa remains a special focus and priority owing to its developmental state and potentials, it was important that, according to the principle of ownership, Africa inscribe their priorities in the 2030 Agenda. The records that the two Agendas are being used side-by-side in the implementation process for African states creates greater advantage in addressing the priorities, thereby deviating from the status quo of one-size-fits-all approach in international development policy and the results thereof.

Over and above these is the ample opportunity the transition from the Millennium Development Goals (MDGs) to the Agenda 2030 for Sustainable Development presents to the Africa's renewal agenda. The MDGs, despite their global outlook, was a wake-up call to ownership by African States and are at the origin of reforms at the regional level of the African Union 
Commission. It was also the motivation behind the Africa's renewal move which culminated in the establishment of the New Partnership for Africa's Development (NEPAD) at the wake of the millennium. In the same vein, the quest for aid effectiveness to reinforce the implementation of the MDGs indeed popularised ownership and results-based approach in Africa. As continuity in this trend, the Agenda 2030 for sustainable development as a results framework its embodiment of reinforcing institutions for effective implementation presents an opportunity for solutions to Africa's development deadlocks which still manifest in ineffective institutions and lack of political will.

The thesis of "begging bowl politics" and "plus ca change, plus c'est la meme chose", as advanced by Akinriande (2003), makes reference to overreliance on development aid and assistance by African states (begging bowl) and the phenomenon of "little or no change to show for increasing development efforts" (plus ça change plus c'est la même chose) in the French language. From post-independence Africa to the late 1990s, dependency on development "aid and assistance as well as reforms without significant change have been a strong part of the African story. However, the adoption of the MDGs in the year 2000 was a big departure from the "begging bowl politics" when the issue of ownership and equal partnership by Africa and the West were brought to the table and there was a clear engagement by African leaders to own their development trajectories. By this engagement and the series of actions and institutional arrangements that followed, Africa's renewal, drawing on efforts to renew the interplay of economic, politics and institutional arrangements to change Africa's fortune from underdeveloped, to a developed continent with the active participation of Africans and African leaders came to the fore. It is taken therefore that the political-economy of Africa's renewal dwells first on the issue of ownership, whereby there were renewed engagements by African Governments to take their destinies into their own hands at the aftermath of the adoption of the MDGs, while the embrace of a "results culture, Africa emergence and institutional reforms for aid effectiveness is dubbed the "New" Political Economy of Africa's renewal.

For us, the so-called "new political-economy of Africa's renewal" is indeed focused on innovations and review of criteria for measuring results to increase the impacts of development actions to leverage the present economic growth potentials and emergence as a new investment destination. The failure of many African states to restructure the postcolonial state and the level of dependence on donor states has been a factor in the identity of the continent as a weak, repressive, feeble, fragile, dependent, and collapsing from the early 70s onward. This weak development situation has always drawn attention to it as a priority continent in aid and assistance within the international community. The "Priority Africa" scheme within the UN system, for example, reflects actions towards a continent that could not stand on its own unless assisted. In fact, McGowan and Smith (1988) categorically stated that African countries' have little decision latitude in their attempts to devise policies appropriate to overcoming underdevelopment.

Looking at progress since the MDGs implementation and the present offerings of the Agenda 2030 for Sustainable Development which come with a rectification of "leaving no one behind", as well as a results framework that leaves room for reforms to meet the heights of objectives, targets and indicators, the SDGs are poised to be an accelerator for the so-called new political-economy of Africa renewal. This is also in the sense that, reinforcing institutional effectiveness is integrated as a standalone goal, the necessity of reform for an integrated development policy that covers all sectors, which will necessitate "programme nexus" across board rather than strict administrative and management procedures, will improve on the Africa's status quo to match the economic emergence. Africa achieved remarkable economic growth performance of about 5.0 percent between 2001 and 2010 - a development which made it possible for twenty 
six countries to be classified as middle-income countries in 2016, against just nine in 2000 . These features characterise African as a new and "emerging" investment destination with a better future, but great efforts for institutional renewal. "Ownership" and "results culture" as new focus for renewal will be strengthened in the process of the SDGs implementation and the impact of this will reshape the development landscape in the Africa of the future. This interpretation of evidence and projection for the future of development in Africa and how the SDGs implementation will shape international development, Africa's geopolitics and political-economy are elements that call for greater attention in the near future.

The Synergy between African Union Agenda 2063 and the Agenda 2030 for Sustainable Development is another opportunity for Africa in streamlining efforts to achieve sustainable development. The African Union Agenda 2063, adopted in 2013 is a strategic framework for the socio-economic transformation of the continent over the next 50 years. The Agenda 2063 built on Lagos Plan of Action, The Abuja Treaty, The Minimum Integration Programme, the Programme for Infrastructural Development in Africa (PIDA), the Comprehensive Africa Agricultural Development Programme (CAADP), The New partnership for Africa's Development (NEPAD), Regional Plans and Programmes and National Plans. It gives cognizance to national, regional, continental best practices in its formulation and seeks to accelerate the implementation of past and existing continental initiatives for growth and sustainable development in Africa.

According to the 2017 Africa Sustainable Development Report, there is a substantial convergence between the Agenda 2030 and the African Union Agenda 2063 at the level of goals, targets and indicators (AU et al, 2017). It is worthy of note that the Agenda 2030 and the African Union Agenda 2063 are being implemented side-by-side by Governments, the UN, other development agencies and development stakeholders in Africa. A good example is the fact that the two Agendas are now integrated in UNESCO present programme planning framework. This in itself supports the thesis of the sustainable development serving as a management tool. It is believed that the integration of the two important development frameworks of importance to Africa by institutions is a growing phenomenon that proves that the holistic approach to development planning and management is being institutionalise and this synergy is giving impetus to the priority Africa efforts by international organizations while helping countries with integrated multisectoral approach to planning and implementation. This positive trend will of course continue to shape development action. For Africa it is indeed an opportunity that will reinforce capacity building and coordination of efforts for improved delivery.

\section{The SDGs and What "Data" will Change for Africa?}

The question of what data will change for Africa in the SDGs dispensation is inspired by a "2017 Africa Sustainable Development Report: Tracking Progress on Agenda 2063 and the Sustainable Development Goals" by the United Nations Economic Commission for Africa (UNECA), in collaboration with the African Development Bank, the African Union, and the United Nations Development Programme (UNDP). According to the report,

Approximately six out of every ten SDG indicators cannot be tracked in Africa due to severe data limitations. Strengthening statistical systems in Africa is an imperative for successful implementation of the SDGs and Agenda 2063 as it underpins evidence based policy making. Disaggregated data by age, gender, income and geographical location is necessary to better target support to 
groups at risk of being left behind in the development process [AU et al, (2107), p. viii].

The report explored the progress that the continent has made towards the SDGs while identifying the data gaps facing policymakers and implementers and concludes that in many areas, especially in health, where data is more available, Africa is making progress. This is while 62 percent of the 232 indicators that measure performance towards the 17 Goals are not traceable in Africa due to severe data limitations (AU et al, 2107).

According to the World Bank's Chief Economist for Africa, Shanta Devarajan, the state of development data in Africa amounts to nothing less than a statistical tragedy, as due to data unreliability, little is known about the growth and income of African economies( Jerven, 2013) ${ }^{1}$. A good example was the scenario that brought Nigeria into becoming the number one economy in Africa in 2014, due to an economic rebase that has not been done in two decades. All the while, global statistics is oblivious of the fact that Nigeria had surpassed South Africa to become the biggest economy in Africa and the third fastest growing economy in the world with a GDP of about $\$ 594$ billion. It was simply discovered that Nigeria had surpassed South Africa in GDP growth by a huge gap of about $\$ 253$ billion. This is what the data gaps do to Africa.

The report attributes the poor availability of data to inefficiencies at the local statistics collecting agencies, as only 12 of the 54 countries in Africa have autonomous statistics offices. National statistics offices are often plagued by insufficient funding and a lack of autonomy. The quality of data, where they are available is another challenge (Sow, 2017).

On the positive note, Africa may have been making more progress than recorded or reported to date, while in the more alarming negative side, the lack of data or its poor quality would remain an impediment to progress, as assessments are difficult and action orientation limited in focus. The situation also debars policy makers from pointing areas of improvement, which ultimately may lead to slow progress or lack of progress at all. The conclusion is that for Africa, tracking SDGs and Agenda 2063 progress is presently a challenge due to data limitation.

Thus, data availability and the pursuit of progress in this regard must be a priority as this will boost the achievement of the SDGs in two ways - establishing proofs of progress and improving on policies based on informed decision. Indeed, identify specific gaps will make a country's progress towards achieving the SDGs even more successful. It is therefore predictable that the pursuit of capacity building actions for SDGs implementation would be more oriented, inter alia, to institutional mechanism, manpower and partnerships for improved data collection.

\section{Conclusion}

The ambitions of the Agenda 2030 for Sustainable Development as a results framework, its universality and overarching objective of leaving no one behind have contributed to a paradigm shift in the ebbs and flows of international development. This is to a greater extent very obvious. And the fact that the SDGs are opportunities and challenges for international development are stressed beyond reasonable doubt in the analysis of this essay.

In examining the development impacts and results framework of the Agenda, the so-called ebbs and flows are seen to have been influenced by quests for development results both at the

${ }^{1}$ See African Economic Development: Measuring Success and Failure, a conference organized by Morten Jerven at the School for International Studies, Simon Fraser University, Vancouver, Canada, April 18-20, 2013, Simon Fraser University, Harbour Centre, Retrieved on 1st June 2018 from : https://www.aehnetwork.org/wp-content/uploads/2016/03/Provisional-Programme-forAfrican-Economic-Development-Measuring-Success-and-Failure.pdf 
international, regional and national levels of engagement. The Agenda as a Universalist, integrated international development framework shows that international classifications and geopolitics of development may find alternatives appellations in a near future, while focus on local impacts will become the major essence of international development endeavours. Creating institutions that are fit for purpose, both at the level of the United Nations and in countries, is beneficial to advancing development, while the inclusion of provision for effective institution for successful implementation of the goals is both a saving grace for continued reforms in the United Nations system and an opportunity for countries to improve on efficiency for programme nexus and national development planning through the SDGs implementation especially in Africa. Some of these assertions also support the thesis that sustainable development as a phenomenon is becoming a management toolkit in international development. The United Nations, which has laid the foundation of reforms to fit the Agenda's purpose is, no doubt, ready to take the opportunity the SDGs offer to reposition itself for more effective and efficient systems of development management action.

African countries with a history of struggle for effective states' institutions should benefit from reforms to implement the SDGs, as the policy continues to promote ownership and results culture for development effectiveness. The quest for an African data revamp is imminent at present and is highly recommended This will make a difference, not only in clearly determining progress, but also in making informed improvement towards the realization of the SDGs by the target date.

Although still early to suggest that the Agenda 2030 is a perfect answer to global development, its influence on the ebbs and flows of international development is beginning to be obvious. The interrogations and debates on what will be the relics of policies, results, impacts and review process beyond 2030 will however continue to linger.

\section{References}

[1] S. AKINRINADE (2003): 'The New Partnership for Africa: Dispensing with the Begging Bowl or Plus ça change, plus c'est la même chose?', In Obadare, E. and Oyewole, D. (Eds.), The New Partnership for Africa's Development (NEPAD). Challenges and Developments. Lagos, pp.128.

[2] AU, UNECA, AFDB, UNDP (2017): Africa Sustainable Development Report:Tracking Progress on Agenda 2063 and the Sustainable Development Goals, UNECA, September, 2017 (Online):https://www.3psmars.org/wp-content/uploads/gravity_forms/1a2396e58f415ec95b0a17c4fc0c8f342/2018/11/Africa-Sustainable-Development-Report-2017en_agenda2063_sdg-web.pdf (Accessed 8 June 2018).

[3] M. BEISHEIM (2016): Follow-up and Review - Developing the Institutional Framework for Implementing and Reviewing the Sustainable Development Goals and Partnerships, Working Paper, Division Global Issues, Stiftung Wissenschaft und Politik German Institute for International and Security Affairs

[4] H. BRUECK (2018): Bill Gates says we need to stop splitting the world into developed and developing, Business Insider, 16th April 2018 (Online) https://www.weforum.org/agenda/2018/04/bill-gates-says-he-now-lumps-the-the-world-into-4income-groups-here-s-how-it-breaks-down (Accessed 7 June 2018).

[5] F. CHIDOZIE, O. O. AJE (2017): International Organizations and Global Governance Agenda: SDGs as a Paragon, Relationes Internationales, Acta Universitatis Danubius, Vol. 10, no. 1/2017, pp. 43-60. 
[6] ECONOMIC COMMISSION FOR AFRICA (UNECA): Common African Position on the Post-2015 Development Agenda, UN Sustainable Development Goals Knowledge Platform.

[7] H. GIGZEN (2018): UN Reform, both a Challenge and an Opportunity for UNESCO, Perspective 2030, UNESCO Strategic Transformation Newsletter, September, 2018.

[8] HOUSE OF COMMONS INTERNATIONAL DEVELOPMENT COMMITTEE (2016): UK implementation of the Sustainable Development Goals: First Report of Session 2016-17, $8^{\text {th }}$ June, 2016.

[9] M. Y. KATAGUM (2016): Agenda 2030 for Sustainable Development - "Transforming Our World": Challenges and Opportunities for Nigerian Tertiary Education Institutions, 4th Convocation Lecture of the Kwara State University (Kwasu), Malete, Kwara State, Nigeria. Delivered on 3rd June, 2016.

[10] A. LEBADA (2018): An Annotated Guide to the UN Secretary-General's Reform Proposals, IISD SDG Knowledge Hub, 23 January 2018 (Online) http://sdg.iisd.org/commentary/policy-briefs/an-annotated-guide-to-the-un-secretary-generalsreform-proposals/ (Accessed 23 April, 2018).

[11] A. LEBADA (2018) September 2018 Update on UN Reform Processes, SDG Knowledge Hub, 6 September, 2018 (online) http://sdg.iisd.org/commentary/policy-briefs/september-2018update-on-un-reform-processes/ (Accessed 16 September 2019).

[12] P.J. MCGOWAN, D. L. SMITH (1978): Economic Dependency in Black Africa: An Analysis of Competing Theories International Organisation 32(1):179-235.

[13] A. MEIDAN (2018): What is International Development? Society for International Development (SID), Israel Branch, 11th March 2018 (online) https://www.sidisrael.org/en/Development-Issues/What-is-International-Development (Accessed 16 May 2018). [14] OECD (2016): Results-Based Decision making in development Cooperation- Development co-operation under the 2030 Agenda: Results and relevance - Discussion note, Results Team, DAC / DCD / REED, August 2016.

[15] OECD (2017): Capturing the 2030 Agenda in development co-operation results: SDGs, targets, indicators, and 'Leave no one behind'- Concept paper for two Task Teams of the Development Assistance Committee (DAC) Results Community, April-September 2017.

[16] OECD (2017): Measuring Distance to the SDG Targets: An assessment of where OECD countries stand, June -2017

[17] OECD (2017): Strengthening providers' results frameworks through targets \& indicators of the Sustainable Development Goals (SDGs), Prepared by the Results Team, OECD Development Co-operation Directorate.

[18] A. OLADELE (2009): Sustainable Development: On the Dilemma of a Definition, Conference of the International Journal of Arts and Sciences, Vol. 1(19): 80 - 95 (2009).

[19] A. OLADELE (2018): The New, the Many, the Connected and the world of FROG, GEOpolity and JAZZ: Revisiting Global Development Scenario in the SDGs Era, 3psmars Analytics 5 June 2018 (Online) https://www.3psmars.org/revisiting-the-new-the-many-connectedand-the-world-of-frog-geopolity-and-jazz-global-development-scenario-of-in-the-mdgs-era/ (Accessed 13 July, 2018).

[20] D. PAUL (2016): Five Ways the SDGs Are Changing International Development, SDG Knowledge Hub, 9 February, 2016 (Online) http://sdg.iisd.org/commentary/policy-briefs/fiveways-the-sdgs-are-changing-international-development/ (Accessed 3 April 2018).

[21] H. ROSLING, O. ROSLING, R.A. ROSLING (2018): Factfulness: Ten reasons We're Wrong about the World - and why things are better than you think, Sceptre, London.

[22] A. SACHS, A. KUNDU (2015): The Unfinished Business of Organizational 


\section{Technium Sustainability}

Transformation, Thouthgtworks, (online)

https://www.thoughtworks.com/insights/blog/unfinished-business-organizational-transformation (Accessed 2 June, 2018).

[23] S. KINDORNAY S. TWIGG (2015): Establishing a workable follow-up and review process for the Sustainable Development Goals, a Report of the Oversees Development Institute (ODI), April, 2015

[24] M. SOW (2017): Figure of the week: Africa's progress on the SDGs and Agenda 2063 Africa in Focus- Brookings, Thursday, November 16, 2017 (Online) https://www.brookings.edu/blog/africa-in-focus/2017/11/16/figure-of-the-week-africas-progresson-the-sdgs-and-agenda-2063/ (Accessed 7 April 2019).

[25] THE GLOBAL CITIZENS' INITIATIVE (TGCI) (n.d.): Thinking Globally and Acting Locally Revisited (Online): http://www.theglobalcitizensinitiative.org/thinking-globally-actinglocally-revisited/ (Accessed 12 June 2018)

[26] M. P. TODARO, S. C. SMITH (2006): Economic Development, 9th Ed., Harlow: Pearson Addison Wesley series in economics Harlow, England.

[27] UNITED NATIONS ESCAP (2016): Follow-up and Review for the Sustainable

Development Goals and the 2030 Agenda for Sustainable Development in Asia and the Pacific a background note on Expert dialogue on effective follow-up and review of the 2030 Agenda for Sustainable Development in Asia and the Pacific, 1-2 December 2016, United Nations Conference Centre, Bangkok.

[28] UN-HABITAT (2016): SDG Goal 11 Monitoring Framework: a Guide to Assist National and Local Governments to Monitor and Report on SDG Goal 11 Indicators, February 2016.

[29] UNDG (2016): The Sustainable Development Goals are Coming to Life: Stories of Country Implementation and UN Support, United Nations Development Group (2016).

[30] UNITED NATIONS (2018): Working Together: Integration, Institutions and the Sustainable Development Goals - World Public Sector Report 2018.

[31] UNITED NATIONS DEVELOPMENT GROUP (2016): Mainstreaming the 2030 Agenda for Sustainable Development, Reference Guide to UN Country Teams, UNDG, February 2016. [32] UNDESA, INTOSAI DEVELOPMENT INITIATIVE (2017): Auditing Preparedness for Implementation of Sustainable Development Goals: Guidance for Supreme Audit Institutions [33] UN -ECOSOC (2017): Repositioning the UN development system to deliver on the 2030 Agenda - Ensuring a Better Future for All: Report of the Secretary-General, 30th June 2017. [34] UN DEPARTMENT OF ECONOMIC AND SOCIAL AFFAIRS (N.D.): Public Institutions for Sustainable Development Goals (online) https://publicadministration.un.org/en/Themes/Public-Institutions-for-SDGs (Accessed 11 June, 2018).

[35] UNITED NATIONS (2018): Working Together: Integration, Institutions and the Sustainable Development Goals - World Public Sector Report, New York.

[36] C. WAKEMAN (2015): Personal Accountability and the Pursuit of Workplace Happiness, Forbes, October 26th, 2015 (Online) https://www.forbes.com/sites/cywakeman/2015/10/26/personal-accountability-and-the-pursuitof-workplace-happiness/\#346b5d8a1ca2 (Accessed 2 June, 2018).

[37] WORLD BANK (N.D.): Country and lending Groups; Country Classifications (Online) https://datahelpdesk.worldbank.org/knowledgebase/articles/906519-world-bank-country-andlending-groups (Accessed 30th June 2018). 